\title{
Comparison of Respiratory Outcome between Sustained Lung Inflation and Intermittent Positive Ventilation in Preterm Infants Requiring Resuscitation at Birth
}

\author{
Lamiaa SH. Rehan*, Safaa A. ELMeneza, Heba T. Okda \\ Department of Pediatrics, Faculty of Medicine for Girls, Al-Azhar University, Cairo, Egypt \\ Email: ${ }^{*}$ lameaarehan11111@gmail.com
}

How to cite this paper: Rehan, L.SH., ELMeneza, S.A. and Okda, H.T. (2021) Comparison of Respiratory Outcome between Sustained Lung Inflation and Intermittent Positive Ventilation in Preterm Infants Requiring Resuscitation at Birth. Open Journal of Pediatrics, 11, 125-134.

https://doi.org/10.4236/ojped.2021.111012

Received: March 8, 2021

Accepted: March 22, 2021

Published: March 25, 2021

Copyright $\odot 2021$ by author(s) and Scientific Research Publishing Inc. This work is licensed under the Creative Commons Attribution International License (CC BY 4.0).

http://creativecommons.org/licenses/by/4.0/

(c) (i) Open Access

\begin{abstract}
Background: Sustained lung inflation (SLI) would permit lung recruitment immediately after birth, improving lung mechanics and reducing the need for intubation and subsequent respiratory support in the neonatal intensive care unit among preterm infants. Aim of the Study: To assess the efficacy of initial sustained lung inflation compared to standard intermittent positive pressure ventilation (IPPV) in preterm infants who need resuscitation in delivery room. Methods: This was prospective randomized observational study that was conducted in the delivery room and NICU of A in shames University hospital from February 2019 to September 2019. The study included 115 preterm infants between 26 - 32 weeks of gestation who needed resuscitation at delivery room. The infants were randomly allocated into 2 groups; SLI group: included the preterm infants who received the SLI at initial inflation pressure of $25 \mathrm{~cm} \mathrm{H}_{2} \mathrm{O}$ for 15 seconds using the Neopuff/T piece. IPPV group: preterm infants who received standard resuscitation; IPPV using the self-inflating bag. The heart rate (HR), oxygen saturation $\left(\mathrm{SpO}_{2}\right)$, oxygen requirement, and intubation rate as well as need of surfactant in the delivery room were assessed. All cases were evaluated after admission to the NICU for the need of mechanical ventilation in the first 72 hours of life, death in delivery room or NICU and for bronchopulmonary dysplasia or death at 36 weeks post menstrual age (PMA). Results: The percentage of preterm infants who needed resuscitation was $25.5 \%$ from the total deliveries during the study period. $56.5 \%$ of them received SLI and $43.4 \%$ received conventional IPPV. There were no significant differences between the studied groups regarding gestational age, birth weight. Apgar score, heart rate, oxygen saturation was not significantly increased in the SLI group at fifth minutes of age. The percentage of infants who
\end{abstract}


needed further resuscitation was $20 \%$ in SLI group and $12 \%$ in the IPPV group. There were no significant differences in need for surfactant, CPAP or ventilator among the studied groups. There were no significant differences in relation to complications as $\mathrm{BPD}$, air leak or retinopathy and death between the two groups. Conclusion: This study showed that there was no advantage from use of SLI in delivery room using T-piece upon the conventional IPPV using self-inflating bag.

\section{Keywords}

Sustained Lung Inflation, Preterm Infants, Resuscitation, Delivery Room, Mechanical Ventilation, T-Piece Resuscitator-Self Inflated Bag

\section{Introduction}

At birth, human lungs are filled with fluid which must be replaced by air for infants to breathe properly. Some infants have difficulty in establishing effective breathing at birth and one in every 20 to 30 newborns receive help to do so using PPV.

Sustained lung inflation (SLI) and positive end-expiratory pressure would permit lung recruitment immediately after birth, improving lung mechanics and reducing the need for respiratory support. Previous clinical studies in preterm infants provided promising results. SLIs provide establishing a more homogeneous and effective FRC that would permit the use of less aggressive tidal ventilation [1]. Still controversy results regarding the outcome of this maneuver.

\section{Aim of Work}

To assess the efficacy of initial sustained lung inflation compared to standard intermittent positive pressure ventilation in preterm infants who will need resuscitation in delivery room.

\section{Subjects and Methods}

\subsection{The Study Design}

This study was a prospective randomized observational study that was conducted at Ain shams Hospital from February 2019 to September 2019.There was 450 deliveries during this period.

A total of 115 preterm infants aged from 26 - 32 weeks of gestation who needed resuscitation at delivery room were enrolled in the current study. They were randomly assigned in a 1:1 ratio to receive either SLI using T-piece (SLI group) or routine resuscitation using IPPV by self-inflating bag (IPPV group).

\subsubsection{Inclusion Criteria}

Preterm infants with 26 - 32 weeks of gestation who needed resuscitation at de- 
livery room were included in the study.

\subsubsection{Exclusion Criteria}

Patients were excluded from the study if they had major congenital anomalies as congenital heart, cerebral, lung or abdominal malformations. Infants with gestational ages $<26$ weeks or $>32$ weeks were excluded, also if no parental consent.

\subsubsection{Group Classification and Delivery Room Intervention}

The cases were categorized into two groups.

1) Sustained lung inflation group (SLI): This group included 65 preterm neonates who received sustained lung inflation (SLI) maneuver (s). SLI was given using a peak pressure of $25 \mathrm{~cm} \mathrm{H}_{2} \mathrm{O}$ sustained for 15 seconds.

A peak pressure of $25 \mathrm{~cm} \mathrm{H}_{2} \mathrm{O}$ was chosen because this level had been shown to be effective and safe in previous studies [1]. Propermask size through a T-piece resuscitator (Neopuff Infant T-Piece Resuscitator; Fisher \& Paykel, Auckland, New Zealand) was applied.

Infants in this group had the following approach:

- Oropharyngeal and nasal suctioning if needed.

- Pressure-controlled $\left(25 \mathrm{~cm} \mathrm{H}_{2} \mathrm{O}\right)$ inflation sustained for 15 seconds.

- Observed for the next 6 to 10 seconds to evaluate the cardiorespiratory function.

If respiratory failure persists (ie, apnea, gasping) and/or the heart rate was $>60$ and $<100$ beats/min despite CPAP, the SLI maneuver (again $25 \mathrm{~cm} \mathrm{H}_{2} \mathrm{O}$ for 15 seconds) repeated.

If the heart rate remained $>60$ and $<100$ beats/min after the second SLI maneuver, the infant was resuscitated [2].

2) Intermittent positive pressure ventilation group (IPPV).

This groupincluded 50 preterm neonates who were resuscitated according to the AAP guidelines [3]. IPPV was given using the self-inflating bag.

\subsection{In the NICU}

All included preterm infants were subjected to complete history taking, anthropometric measurements, clinical examination, and laboratory investigations. Management was individualized according to the need of each case.

\subsection{Outcome Measures}

1) The primary outcome:

a) Need for MV in the first 72 hours of life.

b) Death at the delivery room.

c) Death during hospitalisation.

2) Secondary outcomes:

- Apgar scores at five minutes.

- Heart rate at five minutes.

- Oxygen saturation at 5 minutes. 
- Endotracheal intubation in the delivery room.

- Surfactant administration in the delivery room or during hospital admission.

- Duration in hours of respiratory support, i.e. nasal continuous airway pressure and ventilation via an ETT considered separately and in total.

- Duration in days of supplemental oxygen requirement.

- Chronic lung disease: the need for supplemental oxygen at 28 days of life; the need for supplemental oxygen at 36 weeks gestational age for infants born at or before 32 weeks gestation.

- Airleaks (pneumothorax, pneumomediastinum, pneumopericardium, pulmonary interstitial emphysema) reported either individually or as a composite outcome.

- Cranial ultrasound abnormalities: any intraventricular haemorrhage (IVH), grade 3 or 4 (IVH) according to Papile classification and cystic periventricular leukomalacia.

- Seizures including clinical and electroencephalographic.

- Retinopathy of prematurity (ROP) (all stages and $\geq$ stage 3).

- Patent ductus arteriosus (PDA) (pharmacologic treatment and surgical ligation.

\subsection{Statistical Analysis}

All data were subjected to revision and validation, then description and analysis on IBM-compatible PC by using SPSS (Statistical Package for the Social Science) program version 22.0.0, Microsoft Office Excel 2007, and GraphPad Prism 6. Descriptive statistics were performed for all studied parameters in the tow studied groups and were presented in the form of mean, median, standard deviation (SD), minimum, maximum, range, and percentages. The comparison between groups regarding qualitative data was done by using the Chi-square test. The comparison between two groups with quantitative data and parametric distribution were done by using independent $t$-test. Whilethe comparison between two groups with quantitative data and Non parametric distribution were done by using Mann-Whitney test. The level of significance was calculated according to the following probability $(\mathrm{P})$ values: $\mathrm{P}>0.05=$ non-significant $(\mathrm{NS}) . \mathrm{P}<0.05$ $=$ significant $(\mathrm{S}) . \mathrm{P}<0.001=$ highly significant $(\mathrm{HS})$.

\section{Results}

Among the 450 delivered newborns; 115(25.5\%) of them were preterm infants and need resuscitation. Most infants were 32 weeks' gestational age $(52.1 \%$ in sustained lung inflation and $47.8 \%$ in the IPPV group) and the overall mean \pm (SD) gestational age was 32 weeks (Tables 1-4).

Table 1 shows that need to 2 nd sustained lung inflation was highly statistically significant in the sustained lung inflation group than a need to 2nd intermittent positive pressure ventilation in the intermittent positive pressure ventilation group. 
Table 1. A comparison between a group of sustained lung inflation and intermittent positive pressure ventilation regarding response to resuscitation.

\begin{tabular}{|c|c|c|c|c|c|c|}
\hline & & SLI group & IPPV group & \multirow{2}{*}{$\begin{array}{l}\text { Chi-square } \\
\text { test. }\end{array}$} & \multirow{2}{*}{$\mathrm{P}$-value } & \multirow{2}{*}{ Sig. } \\
\hline & & No. $=65$ & No. $=50$ & & & \\
\hline \multirow[b]{2}{*}{ Apnea gasping at time of birth } & No & $58(89.2 \%)$ & $44(88.0 \%)$ & \multirow[b]{2}{*}{0.043} & \multirow[b]{2}{*}{0.835} & \multirow[b]{2}{*}{ NS } \\
\hline & Yes & $7(10.8 \%)$ & $6(12.0 \%)$ & & & \\
\hline \multirow[b]{2}{*}{ Need $2^{\text {nd }}$ SLI or IPPV } & No & $30(46.2 \%)$ & $44(88.0 \%)$ & \multirow[b]{2}{*}{21.571} & \multirow[b]{2}{*}{0.000} & \multirow[b]{2}{*}{ HS } \\
\hline & Yes & $35(53.8 \%)$ & $6(12.0 \%)$ & & & \\
\hline \multirow{2}{*}{$\begin{array}{l}\text { Response to resuscitation Either } \\
\text { with SLI or IPPV }\end{array}$} & No & $7(10.8 \%)$ & $6(12.0 \%)$ & \multirow{2}{*}{0.043} & \multirow{2}{*}{0.835} & \multirow{2}{*}{ NS } \\
\hline & Yes & $58(89.2 \%)$ & $44(88.0 \%)$ & & & \\
\hline \multirow{2}{*}{$\begin{array}{l}\text { Needs Intubation response to resuscitation } \\
\text { No (Either with SLI or IPPV) }\end{array}$} & No & $58(89.2 \%)$ & $44(88.0 \%)$ & \multirow{2}{*}{0.043} & \multirow{2}{*}{0.835} & \multirow{2}{*}{ NS } \\
\hline & Yes & $7(10.8 \%)$ & $6(12.0 \%)$ & & & \\
\hline \multirow{2}{*}{$\begin{array}{l}\text { Drug used during } \\
\text { resuscitation }\end{array}$} & -- & $64(98.5 \%)$ & $46(92.0 \%)$ & \multirow{2}{*}{2.837} & \multirow{2}{*}{0.092} & \multirow{2}{*}{ NS } \\
\hline & Adrenaline & $1(1.5 \%)$ & $4(8.0 \%)$ & & & \\
\hline
\end{tabular}

${ }^{\star}$ Chi-square test.

Table 2. A Comparison between (sustained lung inflation and intermittent positive pressure ventilation) regarding type of $\mathrm{O}_{2}$ used device after resuscitation in NICU.

\begin{tabular}{|c|c|c|c|c|c|c|c|}
\hline \multirow{2}{*}{$\begin{array}{l}\text { Type of } \mathrm{O}_{2} \text { used device after } \\
\text { resuscitation In NICU }\end{array}$} & \multirow{2}{*}{$\mathrm{N}$} & \multirow{2}{*}{$\%$} & \multirow{2}{*}{$\begin{array}{l}\text { SLI group } \\
\text { No. }=65\end{array}$} & \multirow{2}{*}{$\begin{array}{c}\text { IPPV group } \\
\text { No. }=50\end{array}$} & \multirow{2}{*}{ Test value $^{\star}$} & \multirow{2}{*}{ P-value } & \multirow{2}{*}{ Sig } \\
\hline & & & & & & & \\
\hline CPAP & 20 & $17 \%$ & $12(18.5 \%)$ & $8(16.0 \%)$ & 0.119 & 0.730 & NS \\
\hline CPAP + Ventilator & 6 & $5.21 \%$ & $6(9.2 \%)$ & $0(0.0 \%)$ & 4.869 & 0.027 & NS \\
\hline Nasal prong & 54 & $46 \%$ & $32(49.2 \%)$ & $22(44.0 \%)$ & 0.310 & 0.577 & NS \\
\hline Nasal prong $+\mathrm{CPAP}$ & 9 & $7.82 \%$ & $4(6.2 \%)$ & $5(10.0 \%)$ & 0.580 & 0.446 & NS \\
\hline $\begin{array}{l}\text { Nasa prong } 1+\text { CPAP } \\
+ \text { Ventilator }\end{array}$ & 8 & $6.95 \%$ & $3(4.6 \%)$ & $5(10.0 \%)$ & 1.266 & 0.260 & NS \\
\hline Ventilator & 18 & $15.65 \%$ & $8(12.3 \%)$ & $10(20.0 \%)$ & 1.267 & 0.260 & NS \\
\hline
\end{tabular}

${ }^{*}$ Chi-square test.

Table 3. A comparison between sustained lung inflation group and intermittent positive pressure ventilationgroup regarding primary outcomes of newborn.

\begin{tabular}{|c|c|c|c|c|c|c|c|c|c|}
\hline & & \multirow{2}{*}{$\begin{array}{l}\text { SLI group } \\
\text { No. }=65\end{array}$} & \multirow{2}{*}{$\begin{array}{c}\text { IPPV group } \\
\text { No. }=50\end{array}$} & \multirow{2}{*}{$\begin{array}{l}\text { Chi-square } \\
\text { test }\end{array}$} & \multirow{2}{*}{$\mathrm{P}$-value } & \multirow{2}{*}{ Sig. } & \multirow{2}{*}{ OR } & \multicolumn{2}{|c|}{$95 \% \mathrm{CI}$} \\
\hline & & & & & & & & $\mathrm{LL}$ & UL \\
\hline \multirow{2}{*}{$\begin{array}{c}\text { Needs MV in the } \\
1 \text { st } 72 \mathrm{hrs}\end{array}$} & No & $47(72.3 \%)$ & $36(72.0 \%)$ & \multirow{2}{*}{$0.001^{*}$} & \multirow{2}{*}{0.974} & \multirow{2}{*}{ NS } & & - & - \\
\hline & Yes & $18(27.7 \%)$ & $14(28.0 \%)$ & & & & 1.015 & 0.446 & 2.311 \\
\hline \multirow{2}{*}{$\begin{array}{c}\text { Death at } \\
\text { delivery room }\end{array}$} & No & $65(100.0 \%)$ & $49(98.0 \%)$ & \multirow{2}{*}{$1.311^{\star}$} & \multirow{2}{*}{0.252} & \multirow{2}{*}{ NS } & - & - & - \\
\hline & Yes & $0(0.0 \%)$ & $1(2.0 \%)$ & & & & - & - & - \\
\hline \multirow{2}{*}{$\begin{array}{c}\text { Death during } \\
\text { hospitalization }\end{array}$} & No & $49(75.4 \%)$ & $39(78.0 \%)$ & \multirow{2}{*}{$0.108^{*}$} & \multirow{2}{*}{0.743} & \multirow{2}{*}{ NS } & & - & - \\
\hline & Yes & $16(24.6 \%)$ & $11(22.0 \%)$ & & & & 0.864 & 0.36 & 2.073 \\
\hline
\end{tabular}

${ }^{*}$ Chi-square test; OR: Odd's ratio; C.I: Confidence interval; LL: Lower limit; UL: Upper Limit. 
Table 4. A comparison between a group of sustained lung inflation and intermittent positive pressure ventilation regarding Secondary outcomes of newborn.

\begin{tabular}{|c|c|c|c|c|c|c|c|c|c|}
\hline & & SLI group & IPPV group & & & & & & \\
\hline & & No. $=65$ & No. $=50$ & value & & & & LL & UL \\
\hline & Mean \pm SD & $7.89 \pm 0.92$ & $7.62 \pm 1.24$ & & & & & & \\
\hline Apgar score at $5 \mathrm{~min}$ & Range & $1-7$ & $1-8$ & 1.350 & 0.180 & NS & 0.788 & 0.556 & 1.117 \\
\hline Heart rate at $5 \mathrm{~min}$ & Mean \pm SD & $134.22 \pm 9.17$ & $135.7 \pm 14.52$ & & & & & & \\
\hline (beat $/ \mathrm{min}$ ) & Range & $110-150$ & $100-173$ & -0.669 & 0.505 & No & 1.011 & $0.9 / 9$ & 1.044 \\
\hline Oxygen saturation at & Mean \pm SD & $92.2 \pm 3.08$ & $90.7 \pm 6.8$ & & & & & & \\
\hline $5 \min (\%)$ & Range & $85-97$ & $60-98$ & $1.581^{\circ}$ & 0.117 & NS & 0.939 & 0.864 & 1.020 \\
\hline & No & $58(89.2 \%)$ & $44(88.0 \%)$ & & & & & - & - \\
\hline ETI in delivery room & & & & $0.043^{*}$ & 0.835 & NS & & & \\
\hline & Yes & $7(10.8 \%)$ & $6(12.0 \%)$ & & & & 1.130 & 0.355 & 3.60 \\
\hline Surfactant administration & No & $65(100.0 \%)$ & $50(100.0 \%)$ & & & & - & - & - \\
\hline in delivery room & Yes & $0(0 \%)$ & $0(0 \%)$ & NA & NA & - & - & - & - \\
\hline & No & $59(90.8 \%)$ & $45(90.0 \%)$ & & & & & - & - \\
\hline Surfactant in NICU & & & & $0.019^{\star}$ & 0.889 & NS & & & \\
\hline & Yes & $6(9.2 \%)$ & $5(10.0 \%)$ & & & & 1.093 & 0.314 & 3.808 \\
\hline Duration in hour of & Median (IQR) & $241(96-528)$ & $240(72-408)$ & & & & & & \\
\hline respiratory support & Range & 1- 972 hour & $1-1080$ hour & $-0.615 \ddagger$ & 0.538 & NS & 1.000 & 0.998 & 1.001 \\
\hline Duration in day of & Median (IQR) & $11.50(5-27.75)$ & $11(4-20)$ & & & & & & \\
\hline respiratory support & Range & 1- 42 day & 1 - 95 day & $-0.366^{\ddagger}$ & 0.715 & NS & 1.005 & 0.983 & 1.027 \\
\hline & No & $61(93.8 \%)$ & $50(100.0 \%)$ & & & & - & - & - \\
\hline Chronic lung disease & & & & $3.188^{*}$ & 0.074 & NS & & & \\
\hline & Yes & $4(6.2 \%)$ & $0(0.0 \%)$ & & & & - & - & - \\
\hline & No & $56(86.2 \%)$ & $46(92.0 \%)$ & & & & & - & - \\
\hline Air leak in NICU & & & & $0.963^{*}$ & 0.326 & NS & & & \\
\hline & Yes & $9(13.8 \%)$ & $4(8.0 \%)$ & & & & 0.541 & 0.157 & 1.871 \\
\hline & No & $63(96.9 \%)$ & $50(100.0 \%)$ & & & & - & - & - \\
\hline IVH with grade & & & & $1.566^{*}$ & 0.211 & NS & & & \\
\hline & Yes & $2(3.1 \%)$ & $0(0.0 \%)$ & & & & - & - & \\
\hline Seziures clinical or & No & $65(100.0 \%)$ & $49(98.0 \%)$ & & & & - & - & - \\
\hline monitor of EEG & Yes & $0(0.0 \%)$ & $1(2.0 \%)$ & $1.311^{\star}$ & 0.252 & NS & - & - & - \\
\hline & Not done & $65(100.0 \%)$ & $48(96.0 \%)$ & & & & - & - & - \\
\hline Retinopathy & & & & $2.646^{*}$ & 0.104 & NS & & & \\
\hline & Yes & $0(0.0 \%)$ & $2(4.0 \%)$ & & & & - & - & - \\
\hline & No & $31(47.7 \%)$ & $27(54.0 \%)$ & & & & & - & - \\
\hline PDA & & & & $0.450^{*}$ & 0.502 & NS & & & \\
\hline & Yes & $34(52.3 \%)$ & $23(46.0 \%)$ & & & & 0.777 & 0.371 & 1.626 \\
\hline
\end{tabular}

$\cdot$ Independent t-test; ${ }^{\star}$ Mann Whitney test; ${ }^{*}$ Chi-square test; OR: Odd’s ratio; C.I: Confidence interval; LL: Lower limit; UL: Upper Limit. 


\section{Discussion}

Establishing breathing and improving oxygenation after birth is vital for survival and the long term health of preterm infants [5] [6].

This prospective randomized observational study was conducted to assess the efficacy of initially sustained lung inflation compared to standard inflations in preterm infants who needed resuscitation at birth. This study included 450 newborns, $115(25.5 \%)$ of them need resuscitation and divided into group I (65 newborns, 56.5\%) which received the SLI, and group II (50 newborns, 43.5\%) which received the conventional IPPV.

Our results showed that, there was a significant increase of needing 2nd SLI in group I than need of 2nd IPPV in group II.

In agreement with our results, Kirpalani et al. found that in the sustained inflation group $(\mathrm{n}=215), 27$ infants received 1 sustained inflation and 188 received 2 sustained inflations [4].

On the other hand, there was no statistically significant decrease between the two groups regarding apnea or gasping at the time of birth, response to resuscitation, intubation with SLI, and drugs used during resuscitation $(\mathrm{p}=0.835$, $0.835,0.835 \& 0.092$ respectively).

Also, our results in harmony with that by Jiravisitkul et al. and Amani et al. as they found the intubation rate in the delivery room were not different between the two groups either SLI or IPPV [5] [6].

This finding is in disagreement with the findings of Hilman et al. Who demonstrated responses to SLI followed by MV were significantly higher than the responses to SLI alone [7].

In this study, there was a highly significant decrease of respiratory support requirement after resuscitation in NICU (CPAP + ventilator versus nasal prong, nasal prong versus ventilator, nasal prong $+\mathrm{CPAP}$ versus ventilator\& nasal prong + CPAP + ventilator versus ventilator) regarding the type of resuscitation either by SLI or IPPV.

Our results revealed that, sustained lung inflation treatment was associated with a decrease in mechanical ventilation requirement, but no statistically significant decrease between two groups regarding needs MV in the 1 st $72 \mathrm{hrs}$.

This is in agreement with current results, Lindner et al. They found that the SLI treatment was associated with a decrease in mechanical ventilation requirement (61 vs. 70\%), although the difference was not significant [8].

Previous studies by Lista et al. te Pas and Walther, showed that application of SLI significantly decreased the need for mechanical ventilation within $72 \mathrm{~h}$ of life (37\% vs. 51\%) [1] [9].

In the current study, there was no significant decrease regarding death at the delivery room, or during hospitalization.

There was no significant increase between both groups regarding Apgar score at $5 \min (\mathrm{p}=0.180)$.

This in agreement with the experimental intervention by Kirpalani et al., they compared sustained inflations with intermittent positive pressure ventila- 
tion. They found that here was no significant increase between both groups regarding Apgar score at $5 \mathrm{~min}$ [4].

In contrast, El-Chimi et al. found that SLI was associated with a significantly higher 5-min-Apgar score (median 8 versus $7 ; p=0.018$ ) compared to conventional ventilation $[10]$.

In the current study, there were increases in oxygen saturation at $5 \mathrm{~min}$ and HR at 5 min without significant differences between both groups.

There was no significant decrease between SLI or IPPV regarding, ETI in the delivery room.

Our results are in harmony with that by Jiravisitkul et al. and Amani et al. As they found the intubation rate in the delivery room was not different between the studied groups either SLI or IPPV [5] [6].

Similarly, studies by Harling et al. and Lindner et al. Showed no decrease in endotracheal intubation in the delivery room [8] [11].

This was in disagreeing with El-Chimi et al. Finding of SLI resulted, independently, in significantly less need for intubation [11].

There was no significant decrease between SLI or IPPV regarding surfactant administration in the delivery room, or NICU ( $\mathrm{p}=0.835,0.889)$.

Also, according to outcomes by Kirpalani et al. study, showed that surfactant, in the delivery room, and showed no statistically significant differences between groups [4].

In the current study, there was no significant decrease between both groups regarding, duration of respiratory support (hrs and days).

This was in disagreeing with El-Chimi et al. finding of SLI resulted, independently, in significantly shorter duration of respiratory support during NICU admission, in comparison to intermittent inflation [10].

In the current study, there was no significant decrease between both groups regarding, chronic lung disease, an air leak in NICU, IVH with the grade, seizures clinical or monitor of EEG, retinopathy, and PDA ( $p=0.538,0.715,0.074$, $0.326,0.211,0.252,0.104,0.502$ respectively).

Safe care of the preterm infants is mandatory to prevent lung injury and improve the quality of life [12].

\section{Conclusion}

This study showed that there was no advantage from the use of SLI in the delivery room using a T-piece upon the conventional IPPV using a self-inflating bag.

\section{Recommendation}

Further studied may be required to improve respiratory support of preterm infants in delivery room.

\section{Conflicts of Interest}

The authors declare no conflicts of interest regarding the publication of this paper. 


\section{References}

[1] Lista, G., Boni, L., Scopesi, F., Mosca, F., Trevisanuto, D., Messner, H., et al., SLI Trial Investigators (2015) Sustained Lung Inflation at Birth for Preterm Infants: A Randomized Clinical Trial. Pediatrics, 135, e457-e464. https://pediatrics.aappublications.org/content/135/2/e457.short https://doi.org/10.1542/peds.2014-1692

[2] American Heart Association (2010) American Heart Association (AHA) Guidelines for Cardiopulmonary Resuscitation (CPR) and Emergency Cardiovascular Care (ECC) of Pediatric and Neonatal Patients: Pediatric Advanced Life Support. Pediatrics, 117, e1005-e1028.

https://www.heart.org/idc/groups/heart-public/@wcm/@ecc/documents/downloada ble/ucm 318152.pdf https://doi.org/10.1542/peds.2006-0346

[3] Weiner, G.M., Zaichkin, J., Pediatrics, A., et al. (2019) Textbook of Neonatal Resuscitation (NRP). American Academy of Pediatrics.

https://www.amazon.com/Textbook-Neonatal-Resuscitation-American-Pediatrics/d $\mathrm{p} / 1610020243$

[4] Kirpalani, H., Ratcliffe, S.J. and Keszler, M. (2019) Effect of Sustained Inflations vs Intermittent Positive Pressure Ventilation on Bronchopulmonary Dysplasia or Death among Extremely Preterm Infants: The SAIL Randomized Clinical Trial. JAMA, 321, 1165-1175. https://pubmed.ncbi.nlm.nih.gov/30912836/

https://doi.org/10.1001/jama.2019.1660

[5] Jiravisitkul, P., Rattanasiri, S. and Nuntnarumit, P. (2017) Randomised Controlled Trial of Sustained Lung Inflation for Resuscitation of Preterm Infants in the Delivery Room. Resuscitation, 111, 68-73.

https://www.researchgate.net/publication/311662912 Randomised controlled trial of sustained lung inflation for resuscitation of preterm infants in the deliver y room https://doi.org/10.1016/j.resuscitation.2016.12.003

[6] Arafa, A.E., ELMeneza, S.A. and El Hafeez, S.A. (2020) The Relation between Role of Serum Cortisol Level and Response to Various Respiratory Support Strategies among Preterm Infants. Open Journal of Pediatrics, 10, 504-514. https://doi.org/10.4236/ojped.2020.103051

[7] Hillman N.H., Kemp, M.W. and Noble, P.B. (2013) Sustained Inflation at Birth Did Not Protect Preterm Fetal Sheep from Lung Injury. American Journal of Physiology-Lung Cellular and Molecular Physiology, 305, L446-L453.

https://www.researchgate.net/publication/271595277 https://doi.org/10.1152/ajplung.00162.2013

[8] Lindner, W., Hoegel, J. and Pohlandt, F. (2005) Sustained Pressure-Controlled Inflation or Intermittent Mandatory Ventilation in Preterm Infants in the Delivery Room? A Randomized, Controlled Trial on Initial Respiratory Support via Nasopharyngeal Tube. Acta Paediatrica, 94, 303-309. https://onlinelibrary.wiley.com/doi/abs/10.1111/j.1651-2227.2005.tb18431.x

[9] Te Pas, A.B. and Walther, F. J. (2007) A Randomized, Controlled Trial of DeliveryRoom Respiratory Management in Very Preterm Infants. Pediatrics, 120, 322-329. https://pediatrics.aappublications.org/content/120/2/322.short https://doi.org/10.1542/peds.2007-0114

[10] El-Chimi, M.S., Awad, H.A. and El-Gammasy, T.M. (2017) Sustained versus Intermittent Lung Inflation for Resuscitation of Preterm Infants: A Randomized Controlled Trial. The Journal of Maternal-Fetal \& Neonatal Medicine, 30, 1273-1278. 
https://pubmed.ncbi.nlm.nih.gov/27384245/

https://doi.org/10.1080/14767058.2016.1210598

[11] Harling, A., Beresford, M. and Vince, G. (2005) Does Sustained Lung Inflation at Resuscitation Reduce Lung Injury in the Preterm Infant? Archives of Disease in Childhood-Fetal and Neonatal Edition, 90, F406-F410.

https://fn.bmj.com/content/90/5/F406.short https://doi.org/10.1136/adc.2004.059303

[12] ELMeneza, S. (2020) Egyptian Neonatal Safety Training Network: A Dream to Improve Patient Safety Culture in Egyptian Neonatal Intensive Care Units. Eastern Mediterranean Health Journal, 26, 1303-1311. https://doi.org/10.26719/emhj.20.034 